\section{The need to combat stigmatiz- ing dogmas in the midst of the novel coronavirus disease (COVID-19) pandemic}

\author{
Anthonio Oladele Adefuye, ${ }^{1}$ Markes \\ Butler, ${ }^{2}$ Henry Ademola Adeola ${ }^{3}$ \\ ${ }^{1}$ Division of Health Sciences Education, \\ Faculty of Health Sciences, University of \\ the Free State, Bloemfontein; ${ }^{2}$ Free \\ State Provincial Disaster Management \\ Centre, Department of Cooperative \\ Governance and Traditional Affairs, \\ Free State Province, Bloemfontein; \\ ${ }^{3}$ Department of Dermatology, Faculty of \\ Health Sciences, University of Cape \\ Town, Cape Town, South Africa
}

\section{Dear Editor,}

Stigmatization is a putative structural barrier to health-seeking behaviour, and radical education of the populace is crucial to ameliorate its detrimental effects. Even before the classic work of Erving Goffman in $1963^{1}$ on the social psychology of stigma, the practice of fear and avoidance because of the presence of a disease, in particular infectious diseases ${ }^{2}$ and in some cases noninfectious disease ${ }^{3}$ has been in existence in many societies. Similarly, infectious disease stigmatization - a standardized image of the disgrace of certain people that is held in common by community at large, on account of being ill by an infectious disease ${ }^{4}$ - has co-existed with human nature both in the pre- and post-modern era. ${ }^{5}$

At present, the ongoing novel coronavirus disease 2019 (COVID-19) pandemic has created fear and anxiety in many communities globally and this has led to the widespread resurgence of social stigmatization. Instances of prejudice, racial discrimination, the rise of anti-foreigner sentiments and the blaming of certain groups of people for the spread of COVID-19 has been documented in many parts of the world. ${ }^{6-8}$ Intracommunity discrimination and selfimposed isolation have also been reported in some instances where members of a community demanded that roadblocks be placed between them and another part of the community where COVID-19 cases have been diagnosed. The economic hardship precipitated by the prolonged lockdown regulations and social distancing fatigue has quickly transformed the initial positive sentiments enjoyed by healthcare workers, other first responders and COVID-19 survivors to resentment, social stigma and discrimination. ${ }^{9-11}$ Healthcare providers and emergency COVID-19 frontline responders, once celebrated as heroes in many parts of the world, ${ }^{10}$ are now being stigmatized, experiencing rejection, denial of access to facility and harassment from the stigmatizing society. ${ }^{12,13}$ This may have far-reaching psychological effects on these groups of workers critical in combating this pandemic, as seen in many COVID-19 survivors, who now report having emotional distress from stigma, shame, guilt and anger, and require additional supportive psychotherapy. ${ }^{12-14}$

Furthermore, propagation of COVID19 stigmatization has been facilitated by social media and information technology platforms, and many incidents of COVID19 stigmatization have been reported on most social media platforms. ${ }^{8}$ It is plausible that the continuum of preventive care within the context of the current reality should include keeping COVID-19-negative individuals uninfected, while securing optimal care outcomes for those who are positive. However, the self-sabotaging effect of COVID-19 stigmatization can be significant and offers no benefit to public health efforts, as it precipitates harmful behavioural changes such as self or community denial, hiding the illness to avoid discrimination, not disclosing history of recent travel, and unwillingness to seek medical intervention or advice at an early stage of infection. From an enlightened public health management point of view, unbalancing the delicate trade-off between the civil rights of the infected person and that of the rest of the populace poses a potential barrier to providing robust communal health programmes during the COVID-19 pandemic. Stigmas have been reported to change the environment in which infectious disease pathogens exist, allowing the pathogen to create more havoc than without stigmas in place. ${ }^{5}$ This suggest that ongoing COVID-19 stigmatization will not increase our ability to survive the pandemic but rather act as a driver of problematic disease dynamics, undermine governmental efforts to curtail spread and act as a catalyst for failures in protecting public health. Hence, concerted effort should be made to stop the dogma of COVID-19 stigma and prevent stigma-promoting communication. Information technology and social media platforms should be deployed constructively to create stigma-free and ethical contact tracing apps, as well as telemedicine consultation for patients in remote areas, inter alia. Not least, educating all stakeholders (government, society, infected individuals, patient relatives, caregivers and other first responders) would ameliorate the counterproductive aftermath of COVID-19 stigmatization (a list of do's and don'ts can be
Correspondence: Henry Ademola Adeola, Division of Dermatology, Department of Medicine, Faculty of Health Sciences and Groote Schuur Hospital, University of Cape Town, Observatory 7925, Cape Town, South Africa.

Tel.: +27.21.650.3729; Fax: +27.21.447.8232 E-mail: henry.adeola@uct.ac.za

Key words: COVID-19; stigma; health-seeing behaviour; access to healthcare; health education.

Acknowledgments: HAA thanks the South African Medical Research Council (SAMRC) for a mid-career scientist and Self-initiated research grant; and the South African National Research Foundation (NRF) for Research Development Grant (RDG) for rated researchers.

Conflicts of interest: The authors declare no conflict of interest.

Availability of data and materials: All data generated or analyzed during this study are included in this published article.

Ethics approval and consent to participate: Not applicable.

Informed consent: Not applicable.

Received for publication: 11 May 2021.

Revision received: 20 July 2021.

Accepted for publication: 30 July 2021.

This work is licensed under a Creative Commons Attribution NonCommercial 4.0 License (CC BY-NC 4.0).

${ }^{\circ}$ Copyright: the Author(s),2021

Licensee PAGEPress, Italy

Journal of Public Health in Africa 2021; $12: 1419$ doi:10.4081/jphia.2021.1419

found here: https://www.who. int/docs/ default-source/coronaviruse/covid19-stigma-guide.pdf). Above all, governments, policy-makers and citizens must avoid dehumanizing and demoralizing comments and policies.

\section{References}

1. Goffman E. Stigma: Notes on the management of spoiled identity. London: Penguin Group; 1963.

2. Dadun D, Van Brakel WH, Peters RM, et al. Impact of socio-economic development, contact and peer counselling on stigma against persons affected by leprosy in Cirebon, Indonesia-a randomised controlled trial. Lepr Rev 2017;88:2-22. 
3. Baker GA, Brooks J, Buck D, Jacoby A. The stigma of epilepsy: a European perspective. Epilepsia 2000;41:98-104.

4. Smith RA. Language of the lost: An explication of stigma communication. Communication Theory 2007;17:46285.

5. Smith RA, Hughes D. Infectious disease stigmas: Maladaptive in modern society. Communication studies. 2014;65(2):132-8.

6. Devakumar D, Shannon G, Bhopal SS, Abubakar I. Racism and discrimination in COVID-19 responses. Lancet 2020;395:1194.

7. Chen HA, Trinh J, Yang GP. Anti-Asian sentiment in the United States-COVID19 and history. Am J Surg 2020;220: 556-7.
8. Senzo N, Matambo R, Nkosi S. COVID-19 and stigmatisation and discrimination 2020. Accord, April 17, 2020. Accessed May 5, 2020. Available from: https:/www.accord.org.za/analysis/covid-19-stigmatisation-discrimination/

9. Ehrlich H, McKenney M, Elkbuli A. Protecting our healthcare workers during the COVID-19 pandemic. Am J Emerg Med 2020;38:1527-8.

10. Cox CL. 'Healthcare Heroes': problems with media focus on heroism from healthcare workers during the COVID19 pandemic. J Med Ethics 2020;46: 510-3.

11. Dubey S, Biswas P, Ghosh R, Chatterjee S, Dubey MJ, Chatterjee S, et al. Psychosocial impact of COVID-
19. Diabetes Metab Syndr 2020;14:77988.

12. Bagcchi S. Stigma during the COVID19 pandemic. Lancet Inf Dis 2020;20:782.

13. Singh R, Subedi M. COVID-19 and Stigma: Social discrimination towards frontline healthcare providers and COVID-19 recovered patients in Nepal. Asian J Psychiatr 2020;53:102222.

14. Sahoo S, Mehra A, Suri V, et al. Lived experiences of the Corona Survivors (patients admitted in COVID wards): A Narrative real-life documented summaries of internalized guilt, shame, stigma, anger. Asian J Psychiatr 2020;53:102187. 